\title{
Collimator Device
}

National Cancer Institute

\section{Source}

National Cancer Institute. Collimator Device. NCI Thesaurus. Code C49881.

A diaphragm or system of diaphragms made of an absorbing material, designed to define and restrict the dimensions and direction of a beam of radiation. 